\title{
Engineering Educators Pedagogical Training and System of Pedagogical Education Quality Assessment Based on Multi-Criteria Approach
}

\author{
Elena S. Mischenko ${ }^{1 *}$ and José Carlos Quadrado ${ }^{2}$ \\ ${ }^{1}$ FSBEI HE Tambov State Technical University, Tambov, Sovetskaya str., 106, 392000, Russia \\ ${ }^{2}$ Polytechnic University of Porto, Dr. Roberto Frias str., 4200-465 Porto, Portugal
}

\begin{abstract}
The EngineeriNg educaTors pEdagogical tRaining (ENTER) project aims at creating a novel multicultural and international approach for formal post-graduate professional and pedagogical education for engineering educators. It is focused on low cost and convenience, thus strongly based on e-learning technologies, whenever feasible, and designed with the objective of being internationally recognized and accredited. It is proposed a hierarchy of 3 structured educational programs for engineering educators, in the context of the European Qualifications Framework for Lifelong Learning. The methodology and quality assessment system of the developed programs are based on a multi-criteria approach and provide an adequate level of engineering educators training.
\end{abstract}

\section{Introduction}

Engineering education in Russia and Central Asian countries is strongly subject-oriented and based on deep knowledge of fundamental sciences (mathematics, physics, and others). Political and economic environment in these countries is also specifically oriented to development and improvement of engineering education, not concentrating exclusively on business and manufacturing. Global changes in recent decades lead to highly competitive environment in the world market. At present engineering graduates of new generation are increasingly sought after in the world labor market. These graduates must possess all necessary soft skills (both personal and teamwork), collaborative development experience, be capable of more effective and immediate integration into corporate environment, preferably multicultural and international [1-3].

Bologna process facilitates improving awareness about importance of soft skills and market demands (Qualifications Basics of Higher Education in European Territory, approved in Bergen in 2005). As part of Bologna process, many higher education institutions complemented their educational programs with post-graduate courses and project activities, especially in the areas of engineering and business. For example, many engineering programs contained experiments using active education systems, such as

* Corresponding author: int@tstu.ru 
project oriented learning; process oriented learning based on inquiries and CDIO (Conceive Design Implement Operate) concept [4-9].

As programs combine traditional subject courses with other, imitatively or factually oriented towards collaborative interaction, education becomes more comprehensive and requires better qualified educators with real professional experience. Unfortunately, shortcomings of higher education system are widely known in the entire world. It is especially evident in Central Asian countries: many teachers lack professional experience and entrepreneurial experience. Higher-education teaching personnel usually require quite a modest level of professional and entrepreneurial experience for selection and promotion. Indeed, despite constant discussions that it is necessary to pay attention to pedagogical and professional skills of the faculty staff, scientific curriculum still remains the main driver of career progress in the university.

\section{Enter project}

The aim of "EngineeriNg educaTors pEdagogical tRaining" (ENTER) project is to create new multicultural and international approach to formal postgraduate professional and pedagogical education for teachers of engineering subjects. ENTER programs will be accredited at the international level by Estonian Centre for Engineering Pedagogy at Tallinn University. They offer a hierarchy of three structured educational programs for engineering educators in the context of European qualification system for continuous education. This project is jointly financed by EU ERASMUS+ (598506-EPP-1-2018-1-PT-EPPKA2CBHE-JP) program.

The main aim of ENTER project is developing a multilevel module system for pedagogical training of engineering educators based on international networking cooperation and 7 particular project aims:

- Analysis of European practices in the area of effective methods of training highly skilled engineering educators, especially CDIO initiative;

- Development of three programs (basic, fundamental, advanced) for engineering educators with elective set of modules based on modern educational technology, such as elearning;

- Development of technology for creating individual trajectories in engineering pedagogics;

- Development of international cooperation models for implementing modules and distributing results;

- Development of legal support documents and networking collaboration regulations;

- Development of assessment criteria for professional competences possessed by teachers of engineering subjects, and assessment criteria for quality of curriculum;

- Evaluation of pilot programs implementation results.

Development of three international training programs for engineering educators (iPET) will involve thorough analysis of the market and requirements of teachers and institutions of higher education, oriented towards the EU, Russia, and Kazakhstan. Also, possibilities of other markets on North Africa, South America, and Asia will be taken into account. ENTER iPET program, based on CDIO concept, offers the hierarchy of 3 structured educational programs for engineering educators, in the context of European qualification system for continuous education. Also, it is oriented to low cost and convenience, and as such in large extent is based on e-learning technologies, when it is possible. It was developed with the aim of gaining international recognition and accreditation [10-12].

European partners of the project are: University of Porto(Portugal),Tallinn University of Technology(Estonia), DTI University in Dubnica nad Váhom (Slovakia). Partners, implementing the developed programs, are: Agency of Educational Strategies and 
Initiatives Bologna Club (Russia), Association for Engineering Education of Russia, Don State Technical University (Russia), Tambov State Technical University (Russia), National Research Tomsk Polytechnic University (Russia), Vyatka State University (Russia), Academician E. A. Buketov Karaganda State University (Kazakhstan), Al-Farabi Kazakh National University (Kazakhstan), Kazakhstan Association of Engineering Education (Kazakhstan), Kazan National Research Technological University (Fig.1).

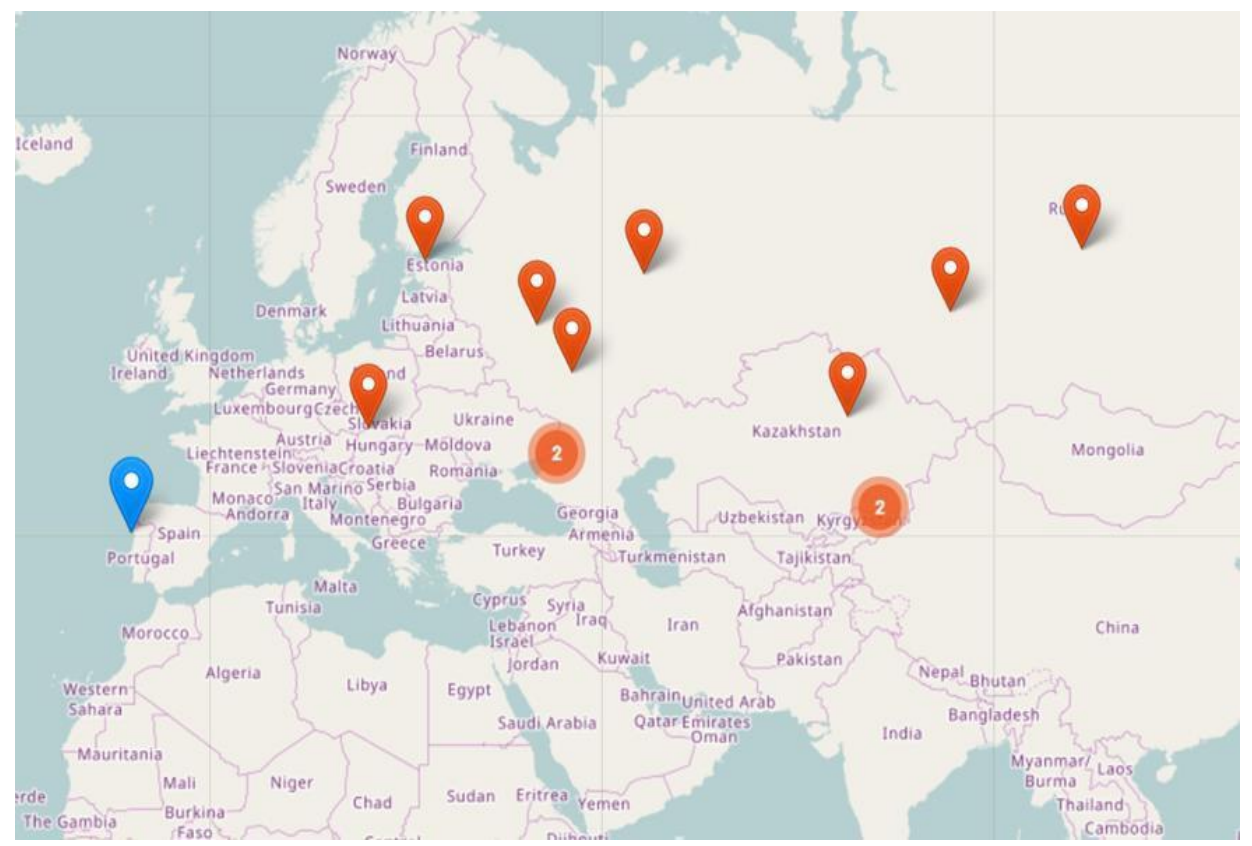

Fig. 1. Project partners.

\section{3 iPET program}

National concept of long-term of social and economic development of the Russian Federation (Development Concept-2020) lists several tasks connected with the national educational problems:

- modernization of teaching technology used in three-cycle system of higher education in order to introduce innovative educational tools including digital ones;

- orientation of educational infrastructure towards greater openness of learning services;

- assistance in educators and students involvement into fundamental and applied research;

- creating conditions for at least $50 \%$ of working age Russian citizens to be engaged in continual learning every year;

- laying down foundation for Russian higher education institutions achieving top positions in international ratings in quality of on-line and off-line learning services.

ENTER turns to national priorities of Russia and Kazakhstan for improving training programs and new technologies in higher education, both from the point of view of innovative education and means for collective learning and support of interdisciplinary activities / cources of engineering programs. The project is intended to become an intermediary for development/improvement of educational programs in these fields. 
ENTER iPET program offers the hierarchy of 3 structured educational programs for engineering educators, in the context of the European Qualifications Framework for Lifelong Learning. Actual design should be one of the results of the project but we envisage 3 educational programs with different content and duration (names are preliminary):

- iPET-1Short-term (for example, 2 credits) -“competence development" certificate;

- iPET-2Professional training for example, credits) -Diploma of a higher education teacher;

- iPET-3 Internationally licensed (for example, 20 credits) - full program, leading to international accreditation «Engineering educator».

iPET programs have module structure, i.e. iPET-1 modules are part of iPET-2, and both are part of iPET-3. This provides a stable path for improvement which pedagogues can take at their own pace. This will also allow educators to join modules from different members of ENTER network. If possible, ENTER will avoid duplicate offers. The project intends to develop a mixed form of learning for conducting courses, including e-learning elements which can be adapted to particular needs of any participating college. By combining on-line and off-line forms of learning we intend to use the best innovative practices of each partner.

As for development and deployment of iPET programs, the project tasks are organized according to the simple «top to bottom» principle:

- determining of demands

- program development

- courses development

- module development and implementation

- final test for fine-tuning and getting feedback from the end user.

\section{Multicriteria approach to assessment of engineering educators training quality}

Analysis of engineering education trends in developed and developing countries shows unprecedented increase in the scale of engineer training. «Engineering boom» of recent years was driven by high demand for knowledge-based professionals in modern economy. A hallmark of engineering education in modern conditions is its fruitful interaction with manufacturing. This interaction results in integration of learning, scientific, and research activities. Engineering institutions get involved in development of new scientific ideas, and their implementation in manufacturing and corporate activities.

Development dynamics of the modern society, perfecting of old and arrival of new technologies present requirements to regular updating of educational programs. In this circumstances quality of engineering educators training gains special significance for engineering institutions.

In this circumstances training courses for engineering educators come not only to obtaining basic or advanced knowledge in engineering pedagogics but to studying subjects, most important to enterprises, partners of the university. This is a two-way cooperation: the enterprises send their employees to the university for training courses including engineering pedagogics programs, and the university forms groups of educators for advanced training with the assistance of leading experts of the enterprises.

Only such two-way cooperation provides for quality training of experts possessing upto-date engineering knowledge, the set of competences, formed by the university together with the partner enterprises. A trend for active international cooperation in this area has emerged in recent years.

A system of comprehensive quality assessment is developed for evaluation of iPET program. The system takes into account all possible factors which can influence the end result in any respect - acquiring competences formed at the initial stage [14]. 
Existing foreign accreditation boards determined a set of parameters characterizing professional training in which the main accent is on the end result. The end result of advanced practical training are professional competence and professional success. The most widely used and acknowledged system of criteria for educational programs assessment are European standards and guidelines for quality assurance in the European Higher Education Area (ESG) [15-16].

This standard and guidelines encompass practically all aspects of educational activities assessment. They also allow evaluating university capabilities of implementing certain programs and can be used as a basis for forming engineering educators advanced training courses quality assessment criteria.

Criteria of membership «Standards and Guidelines for Quality Assurance in the European Higher Education Area» were adopted in 2005 and updated in 2015. Esg is a core document for carrying out expert activities.

ESG is applicable to all higher education institutions and quality assurance agencies in Europe regardless of their structure, functions, size, and country of residence. ESG does not have mandatory aspect and acknowledges importance of universities' and agencies' independence inside national systems.

Standards describe coordinated and accepted practice of quality assurance in higher education. The guidelines explain the importance of the standard and describe methods of its implementation. They show examples of good practice in corresponding areas for analysis by everyone participating in quality assurance. The «quality assurance» term is used to describe all sorts of activities inside the cycle of continuous improvement (i.e. activities for maintaining and improving of quality).

Standards and guidelines for internal quality assurance contain the following criteria:

- quality assurance policy;

- development and approval of programs;

- trainee oriented tuition, teaching, and assessment;

- trainee admission, academic progress, acknowledgment, and certification;

- instructional personnel;

- learning resources and trainee support;

- information management;

- public communication;

- continuous monitoring and periodic evaluation of programs;

- periodic external quality assurance.

Experts, including those in the EQUAR (European Register of Quality Assurance Agenices) register, show special interest to the following aspects: possibilities of work programs correction, participation of targeted enterprises' representatives in forming curriculums, greater education internalization, means of teaching staff monitoring, international cooperation policy, partnership with regional enterprises, conditions of research activities.

Based on the above, and according to ESG guidelines, it is possible to formulate the following engineering educators' training courses quality assessment criteria:

1. Comprehensive evaluation of the professional training courses.

2. Online educational material (OEM), used for classroom and unsupervised activities of trainees.

3. Methods of educational activity.

4. Teaching stuff involved in the educational process.

5. Financial, logistical, and information resources for advanced training courses.

6. Scientific and research activities.

7. Participation of representatives of regional enterprises in the implementation of the educational program. 
8. Maturity level of resulting competences and satisfaction with the results of training of a graduate of professional training courses.

9. Demand for graduates of the program.

Let us look at criteria below and corresponding performance indicators of engineering educators' training courses quality assessment.

Comprehensive assessment of professional development program. It is possible to point out the biggest number of performance indicators for this criterion, including the following ones:

- near-term program development;

- degree of influence of key factors on program implementation (changes in regional trends in education, industrial development of the region, competition);

- are representatives of enterprises involved in the development and implementation of the program;

- whether the system of internal monitoring and quality management of higher education enables the content of the program to be updated in accordance with changing conditions;

- updating of competences and involvement of partner companies' representatives in this process;

- efficiency level of departments involved in the program implemetation;

- how the competency model of a course graduate correlates with the demands of the university;

- how the graduate's competency model correlates with the demands of the university's partner enterprises;

- how the end results of training correlate with the competences being formed;

- relevance of the evaluation fund tools from the perspective of the university and partner enterprises.

Online educational material (OEM) used for classroom and unsupervised activities of trainees. Performance indicators:

- degree of participation in development of online educational material by representatives of targeted enterprises, trainees, and other interested parties;

- updating OEM;

- whether license agreements for software used for development and implementation in the OEM educational process are extended;

- does the OEM include the latest world achievements in the field of engineering pedagogy and specialized subjects of professional training courses;

- does OEM, used in learning process, possess the following qualities: consistency and coherence in the presentation of training material; availability of generalizations and conclusions; availability of control questions and tasks, including test materials; sufficiency and quality of illustrative material; availability of additional literature and hyperlinks to similar online resources on similar topics; sections that allow for a combination of classroom and unsupervised activities.

Procedures for learning activities. Performance indicators:

- educational technologies and methods used in the educational process that contribute to a more complete disclosure of course content and formation of declared competences;

- adequate provision of OEM;

- types of classes used in the educational process;

- degree of implementation of e-learning wiyh the aim of improving quality and availability of training;

- correlation of on-line and off-line learning;

- application of new educational methods, such as: methods of distributed seminars and group activities; on-the-job training and education; remote laboratory workshops; 
- off-line education quality of user-content interaction and interaction between users during off-line training.

Teaching staff (TS) involved in the educational process. Performance indicators:

- existence of a system of training and retraining of the TS in the university, which allows maintaining educators' competence at a level sufficient for the implementation of the course program;

- financial and non-financial motivation of the TS;

- existence of a system of internal monitoring of the TS activities to assess the TS development potential;

- university personnel policy aimed at attracting scientific and pedagogical staff with high competence and qualifications;

- availability of approved requirements for the qualification and competence of teachers involved in the course program;

- share of teachers combining work at the university with their professional activities in partner companies;

- how educators are trained and retrained, documented evidence of systematic professional development;

- how representatives of specialized partner enterprises are involved in the program implementation;

- number of full-time scientific and pedagogical staff implementing programs, conducting research and teaching activities in foreign universities.

Financial, logistical and information resources for advanced training courses. Performance indicators:

- logistical resources for efficient organization oflearning process;

- the extent to which the program's logistical resources allow e-learning to be integrated into the learning process, as well as to improve the mechanisms for its use;

- processes of forming the budget required for implementation of the program of courses, control over its implementation, efficiency of the use of allocated resources during program implementation;

- the extent to which financial resources of the program enable the acquisition, maintenance and operation of facilities and equipment required for the implementation of the program;

- the extent to which the financial resources of the program can provide the learning process with educators and staff with the highest level of qualifications and competence;

- possibilities of information infrastructure designed for creation, storage and delivery of educational content;

- whether trainees and educators have access to the seminal works, major domestic and foreign journals in the area of training and other literature according to the program profile that are not available in the university library through other university libraries and/or electronic information resources available over the Internet.

Scientific research activity. Performance indicators:

- volume of research activities carried out by educators with external and internal funding;

- examples of R\&D carried out through external funding and internal grants, including those of partner enterprises;

- number of scientific publications in leading Russian and foreign journals, patents and certificates of authorship, including with representatives of partner companies.

Participation of representatives of regional enterprises in implementation of the educational program. Performance indicators for this criterion are distributed in the lists above. Additional performance indicators for this criterion are shown further down: 
- how the university's policy on improving education quality encourages the participation of regional enterprises in the course program;

- number of master classes conducted by regional enterprises in the total amount of training sessions under the training program;

- whether representatives of regional enterprises involved in the program provide resources, including financial resources.

Maturity level of resulting competences and satisfaction with the results of training of a graduate of professional training courses. Performance indicators:

- results of a direct assessment of the competences included in the educational program of the courses;

- evaluation by graduates of the quality of interaction between participants in the educational process, relevance and demand for the knowledge obtained.

Demand for the program graduates. Performance indicators:

- results of the analysis of the demand for program graduates (share of the university's TS, share of engineers from targeted enterprises, industrial partners who have received training under the program);

- periodicityof educational program implementation;

- presence of a system for monitoring the demand for graduates of the training program, the impact of the curriculum on the career development of students.

Modern educational programs updating dynamics caused by new discoveries and swiftly evolving technologies presents ever higher requirements to engineering educators [17-20].

Changes in economics and politics, in the professional environment of knowledgeintensive industries and educational environment in recent years have become a catalyst for the emergence of new trends and forms of training, institutional changes in the system of postgraduate and additional professional education, which are reflected in the practice of training of scientific and pedagogical personnel [21-24]. Engineering competence assumes constant updating of knowledge, possession of new information for successful solution of complex tasks [25-28].

Assessment of the quality of professional training courses for engineering educators allows for a comprehensive analysis of both the very possibility of implementation of professional training programs with various degrees of complexity, and formation of tools for improving efficiency of training courses, their adaptation and transformation in accordance with newly emerging urgent engineering problems in close cooperation with partner enterprises.

\section{Distribution and impact}

Teachers for conducting the courses will be selected and instructed within the framework of the project. Finally, programs in 3 pilot courses (iPET-1, iPET-2, and iPET-3) will be unfolded in cooperation with the teaching stuff of participating universities. To avoid slowdown in the course development, two cycles will be employed: the first will be completed in the end of May 2019. At this point preliminary requirements to iPET programs will be presented and discussed. The second cycle is necessary to refine requirements and publish an e-book about pedagogy education best practices for engineering educators.

The project's target audience is presented by teaching stuff of higher education institutions. The main area of activities is engineering education. This target group will be reached through the universities of the consortium and their ties with the teaching stuff, i.e. engineering educators. At the same time Association of Engineering Education of Russia will draw their members (most of them are heads of higher education institutions and 
belong to teaching stuff of more than 70 Russian universities, more than 1600 individual members) to the iPET advanced training program.

\section{Conclusion}

This paper presents the launch of ENTER ERASMUS+ project. The project is aimed at creating a continuing education program to enhance skills of engineering educators. It is a key requirement to modern engineering education, and also the key component of CDIO.

At a greater scale the project will increase competence of engineering educators. As a result the educators will provide more advanced and modern education for university students.

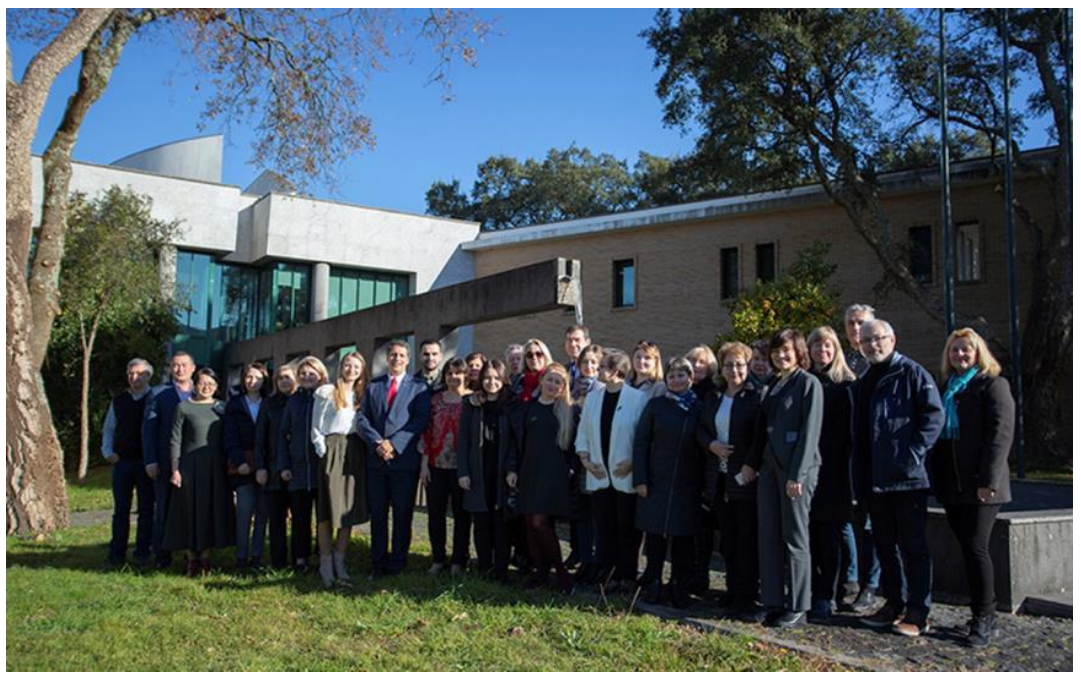

Fig. 2. Initial meeting of ENTER project, January 2019.

\section{Acknowledgement and disclaimer}

This project was jointly financed by the EU Erasmus + program.

This paper reflects only opinions of the authors, and the commission disclaim all liability for any usage of the infortmation contained therein.

\section{References}

1. P.N. Thach, B.N. Phuong, C.C. Dung, L.H. Van \& P.T.H. Diep, A Dynamic Fuzzy Multiple Criteria Decision-making Approach for Lecturer Performance Evaluation, Journal of Management Information and Decision Sciences (2019)

2. J.S. Jeong \& D. González-Gómez, Prioritizing Elements of Science Education for Sustainable Development with the MCDA-FDEMATEL Method Using the Flipped ELearning Scheme, Sustainability, 11(11), p. 3079 (2019)

3. A. Al-Shagran, Assessment of E-learning Systems: A Systems Engineering Approach System (2017)

4. Z. Jianzhong, On cdio model under learning by doing strategy, Higher Education of Engineering, 3, pp. 1-6 (2008) 
5. K.F. Berggren, D. Brodeur, E.F. Crawley, I. Ingemarsson, W.T. Litant, J. Malmqvist \& S. Östlund, CDIO: An international initiative for reforming engineering education, World Transactions on Engineering and Technology Education, 2(1), pp. 49-52 (2003)

6. E.F. Crawley, J. Malmqvist, W.A. Lucas \& D.R. Brodeur, The CDIO syllabus v2. 0. An updated statement of goals for engineering education, Proceedings of 7 th international CDIO conference, Copenhagen, Denmark (2011)

7. K. Edström \& A. Kolmos, PBL and CDIO: complementary models for engineering education development, European Journal of Engineering Education, 39(5), pp. 539555 (2014)

8. J. Bankel, K.F. Berggren, M. Engström, I. Wiklund, E.F. Crawley, D.H. Soderholm, ... \& S. Östlund, Benchmarking engineering curricula with the CDIO syllabus, International journal of engineering education, 21(1), pp. 121-133 (2005)

9. A. Al-Shagran, Towards a Research Road Map for Assessment of E-learning Systems: A Systems Engineering Approach, Proceedings of the International Conference on eLearning, e-Business, Enterprise Information Systems, and e-Government (EEE) (p. 54), The Steering Committee of The World Congress in Computer Science, Computer Engineering and Applied Computing (WorldComp) (2016)

10. R. Dehbi, Model driven engineering applied in e-learning development process: advanced comparative study with ROC multi-criteria analysis, International Journal of Online Pedagogy and Course Design (IJOPCD), 7(1), pp. 15-32 (2017)

11. M. Rüth \& K. Kaspar, The E-Learning Setting Circle: First Steps toward Theory Development in E-Learning Research, Electronic Journal of e-Learning, 15(1), pp. 94103 (2017)

12. D. Vlachopoulos, Assuring quality in e-learning course design: The roadmap, The International Review Of Research In Open And Distributed Learning, 17(6) (2016)

13. T. Rüütmann \& H. Kipper, Klagenfurt School of Engineering Pedagogy by Adolf Melezinek as the Basis of Teaching Engineering, International Journal of Engineering Pedagogy (iJEP), 6(3), pp. 10-18 (2016)

14. S. Farid, R. Ahmad, M. Alam, A. Akbar \& V. Chang, A sustainable quality assessment model for the information delivery in E-learning systems, Information Discovery and Delivery, 46(1), pp. 1-25 (2018)

15. C. Thune, Standards and guidelines for quality assurance in the European Higher Education Area, European Association for Quality Assurance in the European Higher Education (2005)

16. European Association for Quality Assurance in Higher Education (ENQA), Standards and guidelines for quality assurance in the European Higher Education Area (ESG). Brussels: ENQA (2015)

17. A. Krasovsky, S. Vasyukov \& O. Miseyuk, The System Approach for the Application of Measuring Instruments and Computer Modeling Tools for the Electrical Laboratory for the Bauman Moscow State Technical Univercity, 2018 IEEE 59th International Scientific Conference on Power and Electrical Engineering of Riga Technical University (RTUCON), pp. 1-6, IEEE November (2018)

18. V.B. Kamat \& J.K. Kittur, Devising smart strategic framework for assessment of quality in engineering education, International Journal of System Assurance Engineering and Management, 10(6), pp. 1403-1428 (2019)

19. T.D. Margaryan \& N.G. Alyavdina, NEW APPROACES IN TEACHING ENGLISH AT BAUMAN UNIVERSITY, Editorial board, p. 40 (2017) 
20. A. Krasovsky, S. Vasyukov \& O. Miseyuk, The System Approach for the Application of Measuring Instruments and Computer Modeling Tools for the Electrical Laboratory for the Bauman Moscow State Technical Univercity, 2018 IEEE 59th International Scientific Conference on Power and Electrical Engineering of Riga Technical University (RTUCON), pp. 1-6, IEEE, November (2018)

21. M. Zare, C. Pahl, H. Rahnama, M. Nilashi, A. Mardani, O. Ibrahim \& H. Ahmadi, Multi-criteria decision making approach in E-learning: A systematic review and classification, Applied Soft Computing, 45, pp. 108-128 (2016)

22. M.N. Filipe, F.A. Ferreira \& S.P. Santos, A multiple criteria information system for pedagogical evaluation and professional development of teachers, Journal of the Operational Research Society, 66(11), pp. 1769-1782 (2015)

23. J. Vargas, M.C. Moreno \& L. Isaza, Evaluation Model Based on Artificial Neural Networks for the use and Appropriation of Information and Communication Technologies in Higher Education Teachers, International Journal of Applied Engineering Research, 13(12), pp. 10169-10174 (2018)

24. L.A. Kayumova, L.I. Savva, A.L. Soldatchenko, R.M. Sirazetdinov \& L.G. Akhmetov, The Technology of Forming of Innovative Content for Engineering Education, International Journal of Environmental and Science Education, 11(9), pp. 3029-3040 (2016)

25. I. Aouadni \& A. Rebai, Decision support system based on genetic algorithm and multicriteria satisfaction analysis (MUSA) method for measuring job satisfaction, Annals of Operations Research, 256(1), pp. 3-20 (2017)

26. J. Kook, Criteria for selecting the appropriate mobile application development platform for higher education, INSTRUCTIONAL TECHNOLOGY, 73 (2015)

27. E. Kurilovas, J. Kurilova \& T. Andruskevic, On suitability index to create optimal personalised learning packages, International Conference on Information and Software Technologies, October 2016, pp. 479-490, Springer, Cham (2016)

28. E. Kurilovas \& I. Vinogradova, Improved fuzzy AHP methodology for evaluating quality of distance learning courses, International Journal of Engineering Education, 32(4), pp. 1618-1624 (2016) 